\title{
DEFORMATION MONITORING USING PERSISTENT SCATTERER INTERFEROMETRY AND SENTINEL-1 DATA IN URBAN AREAS
}

\author{
Núria Devanthéry ${ }^{1}$, Michele Crosetto ${ }^{1}$, Oriol Monserrat ${ }^{1}$, María Cuevas-González ${ }^{1}$, Bruno Crippa $^{2}$ \\ ${ }^{1}$ Centre Tecnològic de Telecomunicacions de Catalunya (CTTC), ${ }^{2}$ University of Milan
}

\begin{abstract}
In this paper, an approach to Persistent Scatterer Interferometry (PSI) is used to derive deformation measurements over the Catalonia region (Northern Spain). A set of tools to control the quality of the $2+1 \mathrm{D}$ phase unwrapping, one of the key steps of the proposed procedure, are described and applied over a set of Sentinel-1A (S-1A) images. The results, derived using 64 S1-A images comprising the period from March 2015 to May 2017, are analyzed in the last section of the paper. Finally, the deformation velocity map and the time series are described, in particular over the urban areas, where the proposed approach yields the best results.
\end{abstract}

Index Terms- Synthetic Aperture Radar, Sentinel-1, Persistent Scatterer Interferometry, deformation monitoring, urban areas.

\section{INTRODUCTION}

Earth observation from satellite is a key tool for the study of the planet, which makes possible, among other things, the monitoring of different types of natural hazards, contributing to the mitigation of their fatal consequences. Its advantages are manifold: the data acquisition in hazardous or inaccessible areas, the extensive coverage that allows the complete analysis of global phenomena, surpassing the generally more expensive and slow in situ data acquisition. In addition, it provides long-term historical data for large areas, enabling the temporal analysis of different types of phenomena.

In this work, we use images acquired from satellite radar, in particular SAR (Synthetic Aperture Radar) images, to detect and estimate deformations of the terrain using the socalled Differential SAR Interferometry technique (DInSAR). This technique for deformation measurement has achieved significant results in different fields. It was successfully used in the fields of seismology [1, 2], volcanology [3, 4], landslides monitoring [5, 6], glaciology [7, 8], subsidence monitoring $[9,10]$, etc.

In this study, an advanced DInSAR technique is used: the Persistent Scatterer Interferometry (PSI) [11, 12]. PSI has demonstrated to be a powerful tool able to measure and monitor deformation, see [13] for a review, especially over urban areas. This technique uses large stacks of interferometric SAR images to generate deformation maps and deformation time series. In this paper, the images acquired with the ESA satellite Sentinel-1 are used. The characteristics of these images bring important advantages with respect to other images: the wide area coverage of the Interferometric Wide Swath mode, which is 250 by $180 \mathrm{~km}$; the 12-day revisiting cycle of Sentinel-1A (6 days with the Sentinel-1B); the reduced orbital tube; the high image coherence; the acquisition in background mode; and the free of charge data availability.

The processing tools described and used in this paper for the data processing and analysis are related to the so-called 2+1D phase unwrapping described in [14], which represents one of the key steps of the procedure. The results using the approach described in section 2 and 64 S-1A images over the region of Catalonia (Northern Spain) are analyzed in section 3 .

\section{METHODOLOGY}

The procedure is based on a Persistent Scatterer Interferometry approach, the PSIG chain [14]. The PSIG chain, PSI chain of the Geomatics division of CTTC, was aimed at processing wide areas, and was successfully used with Terrasar-X data. In this study, we applied it to S-1 data acquired with the Interferometric Wide Swath (IWS) mode. These images are acquired in TOPS mode and consists of 3 sub-swaths, each of them consisting of 9 bursts. The preprocessing is performed burst wise, to merge them all in a final step to generate the interferograms and amplitude images sub-swath wise.

The PSI procedure is performed sub-swath wise. The inputs are a set of $\mathrm{N}$ images and a redundant network of $\mathrm{M}$ interferograms, with $\mathrm{M} \gg \mathrm{N}$. The main steps of the procedure are described below:

(i) PS candidate selection. In this study we used the Dispersion of Amplitude (DA) criterion.

(ii) 2+1D phase unwrapping, which consists in a spatial phase unwrapping, based on the Minimum Cost Flow method $[15,16]$, followed by a pixel-wise temporal phase unwrapping able to detect and correct the phase unwrapping errors. It is based on an iterative least square procedure [17, 
18, 19] which makes use of the integer nature of the unwrapping errors. For a detailed explanation see [14].

(iii) $2+1 \mathrm{D}$ phase unwrapping quality control. Two main analysis are carried out: 1) Analysis of the plot of the residuals, which displays the residuals (the difference between the estimation at the end of an iteration and the observation) for each point (lines) and each interferogram (columns). This allows easily detecting anomalous points and interferograms, where clusters of residuals are different to zero; 2) Generation of the 3 Class Quality Index Map [1]: "Good" when the ratio between the number of corrections and the number of interferograms connected with an image is less than $30 \%$ for all the images of a given pixel, "Fair" when it is between $30 \%$ and $40 \%$, and "Warning" if it is above $40 \%$ in any of the images. The index is typically used to remove the "Warning" pixels and to study the feasibility of using the "Fair" pixels.

(iv) Atmospheric Phase Screen (APS) estimation using a set of spatio-temporal filters $[12,20]$ and subsequent removal from the original interferograms.

(v) Deformation velocity and Residual Topographic Error (RTE) estimation using the method of the periodogram. In this step, the assumption of a linear deformation model is used. An extension of the twoparameter model can be optionally used to account for the thermal expansion [21].

(vi) Second iteration of the $2+1 \mathrm{D}$ phase unwrapping. This step is performed over the $M$ wrapped interferograms free of APS and RTE to derive the final deformation time series without any assumption on the deformation model. The output is a set of $\mathrm{N}$ deformation estimates per ach pixel, temporally ordered in correspondence to the image dates.

(vii) $2+1 \mathrm{D}$ phase unwrapping quality indexes, which consist in: 1) generation of the 3 Class Quality Index Map; and 2) Generation of a quality index for each image of a given deformation time series, given by the number of corrections associated to each image. This provides a complete information to be used to evaluate the quality of the time series.

\section{DESCRIPTION OF THE RESULTS}

In this study, the Catalonia area (Northern Spain) is covered. This area comprises approximately $31000 \mathrm{~km}^{2}$. A total of 64 S-1A images covering the period from March 2015 to May 2017 were used in the complete processing. The procedure was carried out sub-swath wise. During the $2+1 \mathrm{D}$ phase unwrapping control step, some images were discarded, so the final dataset used was: 60 images in sub-swath 1, 56 images in sub-swath 2 and 59 images in sub-swath 3.

The first stage of the phase unwrapping was performed. The first quality control was performed analyzing the residuals. In this step, some interferograms and images were

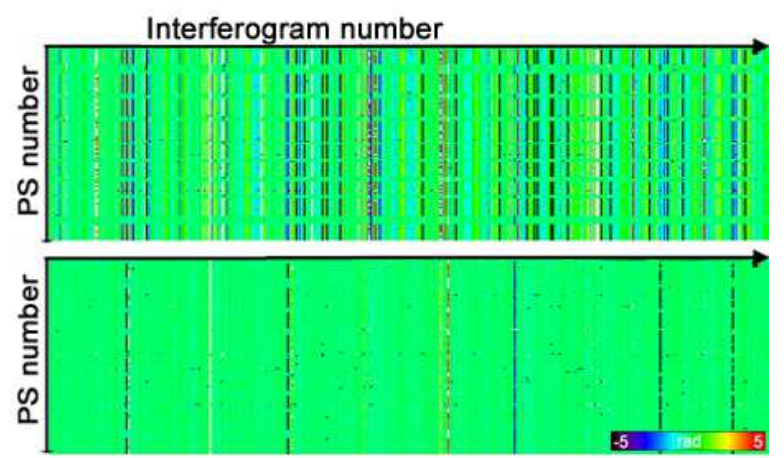

Figure 1. Residuals at the first iteration (top) and last iteration (bottom) of a dataset of 62 images and 807 interferograms. The image only displays the first 400 interferograms.

discarded from the procedure, due to errors generated in the pre-processing steps. Figure 1 shows the plot of the residuals of the $2+1 \mathrm{D}$ phase unwrapping at the first and last iterations, where each line is related to a given PS and the columns refer to the interferograms. Figure 1 is a zoom on the first 400 interferograms of the residuals of a dataset consisting in 62 images and 807 interferograms. From the residuals of the last iteration we detected 16 interferograms with residuals different to zero, all related to the same image, 31/03/2017, which contains an error generated in the co-registration step. This image was removed from the processing.

The second quality control was carried out generating the 3 Class Quality Index Map. For the entire area, 69\% of the PS were identified as "Good", $20 \%$ as "Fair" and $12 \%$ "Warning". Most of the Warning and Fair were found in mountainous areas in the north part of the image. The "Warning" points were discarded for further processing.

The velocity of deformation and deformation time series with their quality indexes were derived following the procedure described in section 2. The velocity of deformation map generated for the whole area contains more than 2800000 measured PSs, mostly concentrated in the urban areas. The standard deviation of the velocity in urban areas is $0.94 \mathrm{~mm} /$ year, while in non-urban areas is 1.14 $\mathrm{mm} /$ year. Figure 2 shows a subset of the velocity of deformation map, which comprises part of the Barcelona and Girona areas. Some major deformations were found: a subsidence in the Sallent area, where there are undergoing mining activities in the upper left part of Figure 2; the subsidence in the town of Montmeló (central part of Figure 2 ); the subsidences in the airport and harbour of Barcelona (bottom of Figure 2). As shown in most of the blue areas in Figure 2, the atmospheric term has a high impact on the measurements in some rural areas. This could be due to the atmosphere related to topography or to a low density of points in the first iteration of the $2+1 \mathrm{D}$ phase unwrapping. It is worth noting that there is a high correspondence between these points and areas with high concentration of "Fair" points in this first iteration. 


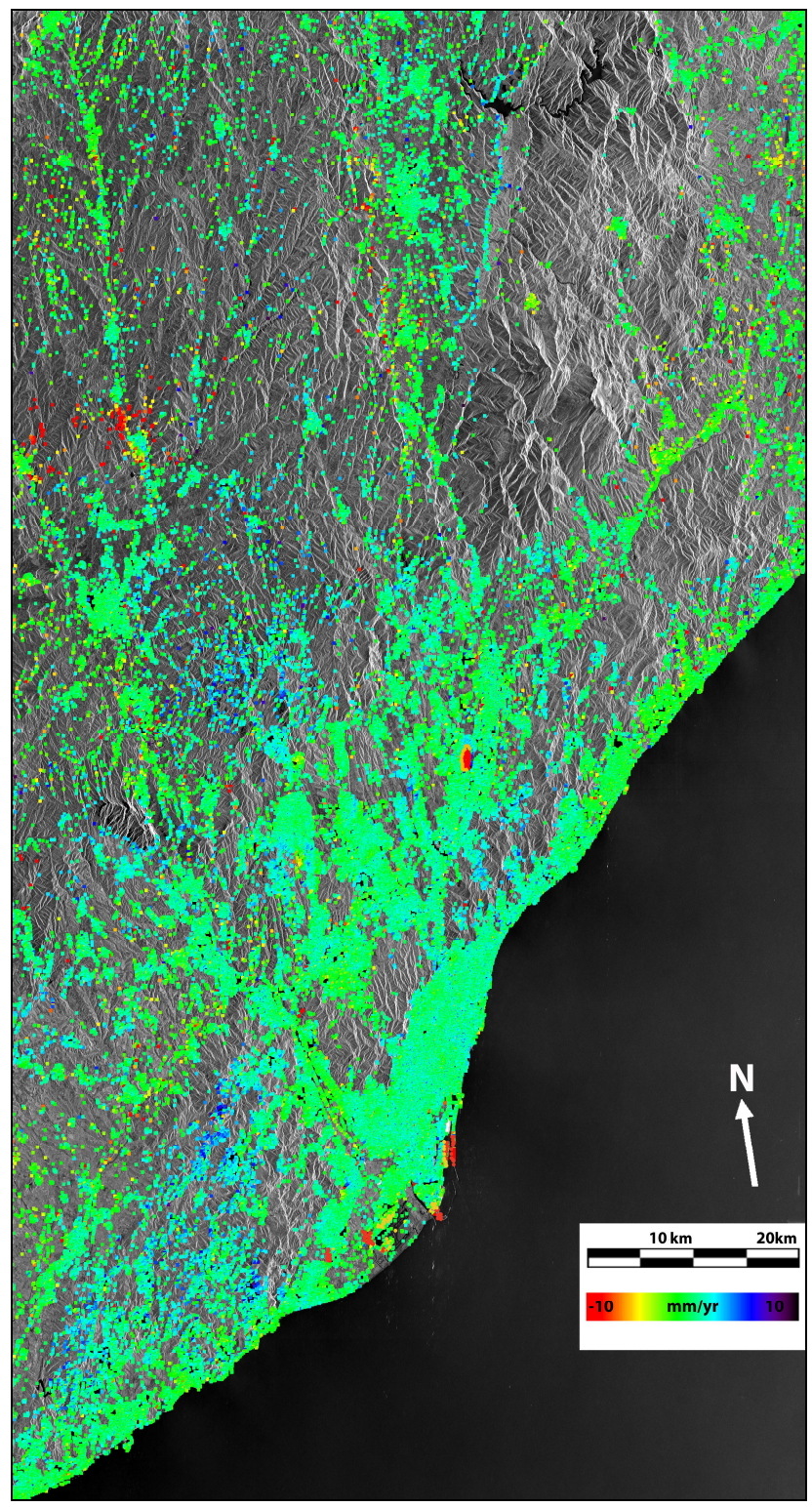

Figure 2. Velocity of deformation map covering the provinces of Barcelona and Girona in the Catalonia area (Northern Spain) superimposed to the mean amplitude image.

Figure 3 shows a zoom over the above mentioned subsidence located in the town of Montmeló (Barcelona), which was geocoded over a Google Earth optical image. The maximum velocity measured in the subsidence reaches 14 $\mathrm{mm} /$ year. This is probably due to underground water extraction. There is also an uplift, with values up to 5 $\mathrm{mm} /$ year. We believe that the deformation is caused by water extraction. A more in depth analysis of this phenomenon is ongoing. In this area, which is densely covered by urban, sub-urban and industrial buildings, all of these PS were classified as "Good" in the Quality Control step. Figure 4 shows the temporal behaviour of the deformation (circle time series) and the quality index associated to each image of the time series (diamonds).

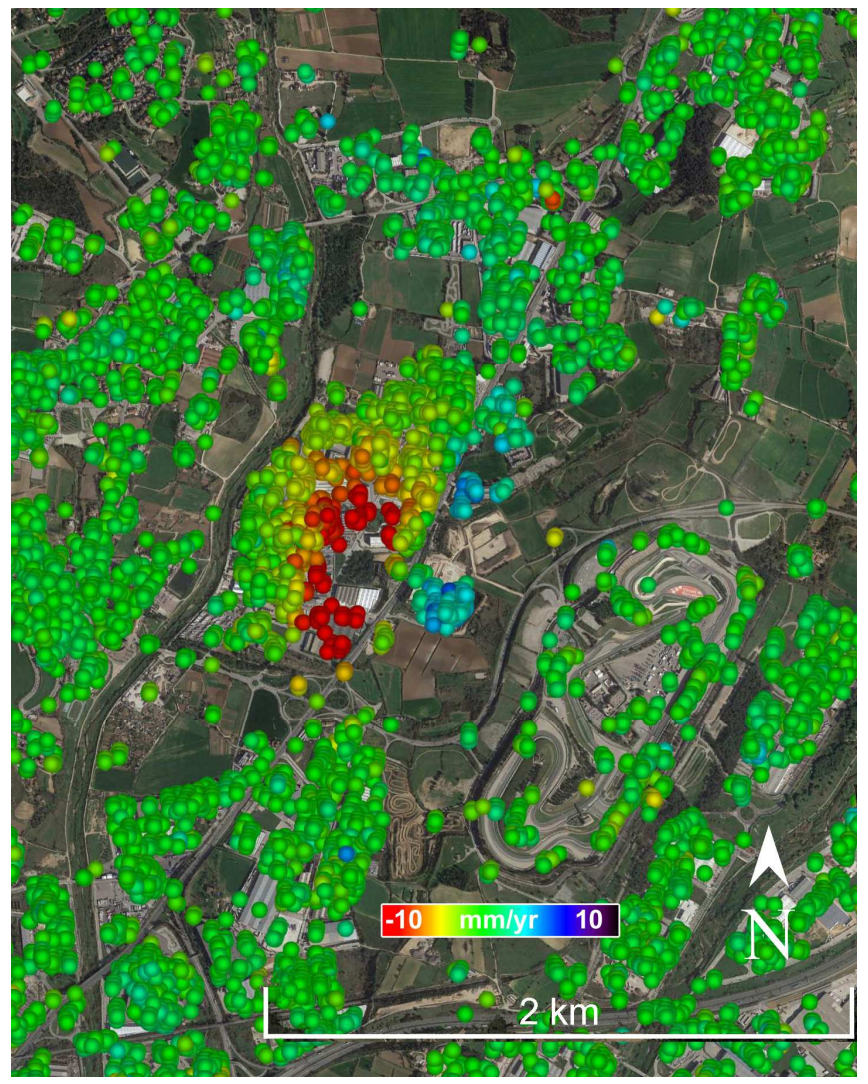

Figure 3. Geocoded velocity of deformation over Montmeló (Barcelona), superimposed to a Google Earth image.

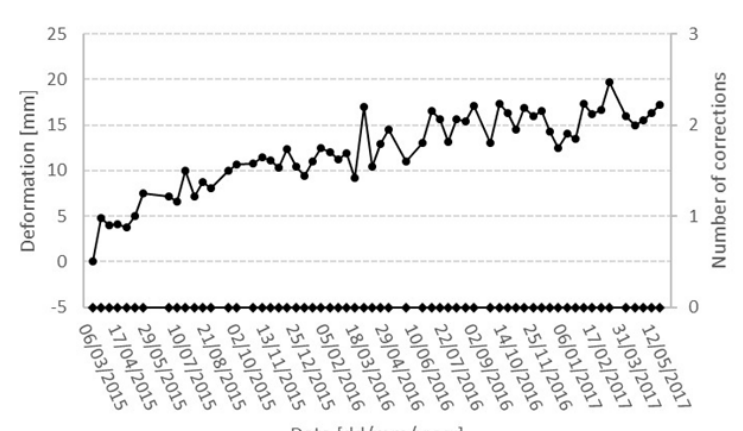

Date [dd/mm/yyyy]

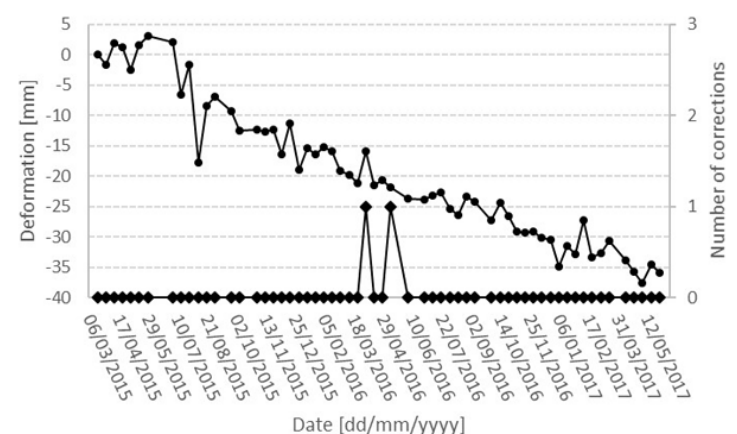

Figure 4. Two examples of time series (circles) of points located in the area of the uplift (top) and the subsidence (bottom) shown in Figure 3. Each image of the time series has associated a quality index (diamonds) 


\section{CONCLUSIONS}

The deformation measurements over the region of Catalonia (Northern Spain) were successfully derived using 64 S-1 images and PSIG chain. The quality control tools of the $2+1 \mathrm{D}$ phase unwrapping have been fundamental to control the results of a key step of the procedure: the phase unwrapping. Three tools have been used: (i) the plot of the residuals, which displays the residuals per point and interferogram allowing the detection of anomalous interferograms; (ii) the 3 Class Quality Index Map used to asses the quality of the phase unwrapping PS wise; and (iii) the quality index per image of each deformation time series, given by the number of corrections associated to each image. These tools have demonstrated to be essential to process big amounts of data.

\section{REFERENCES}

[1] Massonnet, D., Rossi, M., Carmona, C., Adragna, F., Peltzer, G., Feigl, K., Rabaute, T. "The displacement field of the Landers earthquake mapped by radar interferometry". Nature, 364(6433), 138-142, 1993.

[2] Dalla Via, G., Crosetto, M., Crippa, B."Resolving vertical and east $\square$ west horizontal motion from differential interferometric synthetic aperture radar: The L'Aquila earthquake". Journal of Geophysical Research: Solid Earth (1978-2012), 117(B2), 2012.

[3] Massonnet, D., Briole, P., Arnaud, A. "Deflation of Mount Etna monitored by spaceborne radar interferometry". Nature, 375, 567-570, 1995.

[4] Antonielli, B., Monserrat, O., Bonini, M., Righini, G., Sani, F., Luzi, G., Feyzullayev, A.A., Aliyev, C.S. "Pre-eruptive ground deformation of Azerbaijan mud volcanoes detected through satellite radar interferometry (DInSAR)". Tectonophysics, 637, 163-177, 2014.

[5] García-Davalillo, J.C., Herrera, G., Notti, D., Strozzi, T., Álvarez-Fernández, I. "DInSAR analysis of ALOS PALSAR images for the assessment of very slow landslides: the Tena Valley case study". Landslides, 11(2), 225-246, 2014.

[6] Barra, A., Monserrat, O., Mazzanti, P., Esposito, C., Crosetto, M., Scarascia Mugnozza, G. "First insights on the potential of Sentinel-1 for landslides detection". Geomatics, Natural Hazards and Risk, 7(6), 1874-1883, 2016.

[7] Goldstein, R.M., Engelhardt, H., Kamb, B., Frolich, R.M. "Satellite radar interferometry for monitoring ice sheet motion: application to an Antarctic ice stream". Science, 262(5139), 15251530, 1993.

[8] Dematteis, N., Luzi, G., Giordan, D., Zucca, F., \& Allasia, P. "Monitoring Alpine glacier surface deformations with GB-SAR". Remote Sensing Letters, 8(10), 947-956, 2017.
[9] Galloway, D.L., Hudnut, K.W., Ingebritsen, S.E., Phillips, S.P., Peltzer, G., Rogez, F., Rosen, P.A. "Detection of aquifer system compaction and land subsidence using interferometric synthetic aperture radar, Antelope Valley, Mojave Desert, California". Water Resources Research, 34(10), 2573-2585, 1998.

[10] Herrera, G., Tomás, R., López-Sánchez, J.M., Delgado, J., Mallorquí, J.J., Duque, S., Mulas, J. "Advanced DInSAR analysis on mining areas: La Union case study (Murcia, SE Spain)". Engineering Geology. 90(3), 148-159, 2007.

[11] Ferretti, A., Prati, C. and Rocca, F. "Nonlinear subsidence rate estimation using permanent scatterers in differential SAR interferometry". IEEE TGRS. 38(5), 2202-2212, 2000.

[12] Ferretti, A., Prati, C., and Rocca, F. "Permanent scatterers in SAR interferometry". IEEE TGRS. 39(1), 8-20, 2001.

[13] Crosetto, M.; Monserrat, O.; Cuevas-González, M.; Devanthéry, N.; Crippa, B. "Persistent Scatterer Interferometry: a review". ISPRS Journal of Photogrammetry and Remote Sensing, 115, 78-89, 2016.

[14] Devanthéry, N., Crosetto, M., Monserrat, O., CuevasGonzález, M., Crippa, B. "An approach to Persistent Scatterer Interferometry". Remote Sensing, 6, 6662-6679, 2014.

[15] Costantini, M. "A novel phase unwrapping method based on network programming". IEEE TGRS. 36, 813-821, 1998.

[16] Costantini, M., Farina, A., Zirilli, F. "A fast phase unwrapping algorithm for SAR interferometry". IEEE TGRS. 37, 452-460, 1999.

[17] Baarda, W. "A Testing Procedure for Use in Geodetic Networks". Kanaalweg 4, Rijkscommissie voor Geodesie: Delft, The Netherlands, 1968

[18] Björck, Å. "Numerical Methods for Least Square Problems". Siam: Philadelphia, PA, USA, 1996.

[19] Förstner, W. "Reliability, gross error detection and selfcalibration". ISPRS Commission III Tutorial on Statistical Concepts for Quality Control. ISPRS Int. Arch. Photogramm., 26, $1-34,1986$.

[20] Berardino, P., Fornaro, G., Lanari, R., and Sansosti, E. "A new algorithm for surface deformation monitoring based on small baseline differential SAR interferograms". IEEE Transactions on Geoscience and Remote Sensing, 40(11), 2375-2383, 2002.

[21] Monserrat, O., Crosetto, M., Cuevas, M., Crippa, B. "The thermal expansion component of Persistent Scatterer Interferometry observations". IEEE Geoscience and Remote Sensing Letters, 8, 864-868, 2011. 